\title{
Antioxidant and Hepatoprotective Activity of Garlic Chives (Allium tuberosum) Ethanolic Extract on Doxorubicin-Induced Liver Injured Rats
}

\author{
Ika R. Sutejo and Erfan Efendi \\ Departement of Biochemistry, Faculty of Medicine University of Jember, Jember, Indonesia \\ Email: \{ikarahmawati.fk, erfanefendi.fk\}@unej.ac.id
}

\begin{abstract}
The plant phenolic compounds such as flavonoids and isoflavons have an important role in the treatment of many diseases and some of them induce a potent antioxidant and hepatoprotective effect. The objective of this study is to investigate the antioxidant and hepatoprotective activity of flavanoids compound from ethanolic extract of Allium tuberosum (EAT) against doxorubicin-induced hepatotoxicity in male Wistar rats. Preliminary phytochemical tests of EAT were done by Thin Layer Chromatography. Antioxidant and hepatoprotective activity of EAT was evaluated by treating groups of rats with $500 \& 1000 \mathrm{mg} / \mathrm{kg}$ body weight per oral of EAT for 14 days and at the same time (day-1 and day-8) challenging with $4.67 \mathrm{mg} / \mathrm{kg}$ body weight of Doxorubicin. On day-15 the hepatoprotective and antioxidant effects of EAT were evaluated by measuring liver function and MDA serum spectrophotometrically using standard procedures. Thin Layer Chromatography indicate the presence of the flavanoids on EAT. Results showed that intraperitoneal injection of Doxorubicin caused a significant $(p<0.001)$ elevation in the serum levels of SGOT and SGPT. However, elevations in the measured biochemical parameters were significantly $(p<0.05$ and $p<0.01)$ attenuated in rats treated with EAT, in dose related fashion. Oral administration of EAT also decreases levels serum MDA $(p<0.01)$. It can be concluded that ethanolic extract of Allium tuberosum has a significant hepatoprotective and antioxidant activity. In addition, Allium tuberosum may be useful for adjuvant chemotherapy doxorubicin.
\end{abstract}

Index Terms-Allium tuberosum, antioxidant, doxorubicin, SGOT, SGPT

\section{INTRODUCTION}

Chemotherapy is the primary modality of cancer therapy, and the most frequently used is doxorubicin. This drug is effective in treating various types of cancer such as breast, lung, prostate, cervical, bone, etc., [1] but doxorubicin has many side effects including hepatotoxic, cardiotoxic, nephrotoxic, and immunosuppression. [2], [3]

Manuscript received November 10, 2016; revised January 24, 2017.
Doxorubicin affects the hepatobiliary system by inducing an imbalance of oxygen free radicals and antioxidants. Impaired balance of oxidants results in damage of liver tissue. [4] This hepatotoxic activity can be measured using SGOT, SGPT and MDA.

The plant phenolic compounds such as flavonoids and isoflavons have an important role in the treatment of many diseases and some of them induce a potent antioxidant and hepatoprotective effect. [5] One of the potential plants is garlic chives (Allium tuberosum). Garlic chives are smallest species of the family Alliaceae, native plants in Europe, Asia and North America. The aroma of garlic chives is more like garlic than chives, so that in English is called garlic chives. This plant is used as an antibacterial, anti-emetics, treatment of urinary incontinence, bladder weakness, etc. [6]Garlic chives can be harvested up to two times more compared to other types of onions. The price is also very affordable.

Garlic chives are known to contain flavonoids, especially allicin that is proven to increase the number of $\mathrm{CD} 4+$, but that he also has the effect to increase the proinflammatory mediators (IFN- $\gamma$, TNF and NO). [7],[8] Allicin also has hepatoprotector effect, but the mechanism is not certain. [9] The aims of this study is to prove the potential of Allium tuberosum as a hepatoprotective through an antioxidant mechanism of male Wistar rats induced by doxorubicin.

\section{MATERIAL AND METHODS}

\section{A. Plants}

Garlic chives (Allium tuberosum) were collected from P.T GMN Food, Singosari, Malang, Indonesia, in March 2016. The plant was authenticated by a taxonomist at Departement of Botany, Faculty of Mathematics, University of Jember, Indonesia Garlic chives specimens stored in the herbarium of Faculty of Mathematics, University of Jember.

\section{B. Animals}

Wistar rats (weighing 100-150 g) were housed at aconstant temperature $\left(25 \pm 2^{\circ} \mathrm{C}\right)$ with a constant relativehumidity $(60 \pm 10 \%)$ on the an automatically 
controlled 12:12 h light-dark cycle (light on at 7:00 a.m.). Rats werefed with standard rat chow and water as libitum. The ratswere acclimatized and quarantined for at least one weekprior to the experiment.

\section{Research Design}

Thirty seven male Sprague Dawley rats are divided into five groups consisting of 6-7 rats each as follows: 1) normal controls, rats were given $0.9 \% \mathrm{NaCl}$ (Widatra, P.T Otsuka, Indonesia) intraperitoneally, 2) negative control, Doxorubicin rats were given $4.67 \mathrm{mg} / \mathrm{kgW}$ in $0.5 \% \mathrm{CMC}$ $\mathrm{Na}$ po, 3) extracts controls, rats were given EAT 1000 $\mathrm{mg} / \mathrm{kgW}$ in a solvent $0.5 \% \mathrm{CMC}-\mathrm{Na}$ po, 4) first group treatment, Doxorubicin-induced rats $4.67 \mathrm{mg} / \mathrm{kgW}$ ip and at the same time got EAT $500 \mathrm{mg} / \mathrm{kgW}, 5)$ Second group treatment, Doxorubicin-induced Rat $4.67 \mathrm{mg} / \mathrm{kg}$ i.p. and at the same time got EAT $1000 \mathrm{mg} / \mathrm{kgW}$. Induction Doxorubicin (Actavis, obtained from P.T. Actavis Pharmaceutical Bogor, Indonesia)performed on days 1 and 8 . The treatment of EAT were administered for 14 days.

\section{Extraction Method}

Garlic chives which have been dried in the oven smoothed by using a blender. A total of 599.59 grams of chives powder macerated using ethanol $70 \%$ with a ratio of 1: 3. The macerate was filtered using filter paper to obtain the filtrate which then evaporated to obtain as much as 175.56 grams of concentrated extract.

\section{E. Measurement of SGOT and SGPT Serum}

After 2 weeks, the animals were killed and blood samples were obtained using cardiac puncture method. Serum Glutamate Pyruvate Transaminase (SGPT) and Serum Glutamate Oxaloacetate Transaminase (SGOT) levels were measured using spectrophotometery method (Dialab).

\section{F. Measurement of MDA Serum}

$100 \mathrm{~mL}$ of blood serum and $10 \mathrm{~mL}$ of BHT solution (TBARS Assay kit, Bioassay)mixed in a glass tube. Successively added $700 \mathrm{~mL}$ of $1 \%$ orthophosphoric acid and $200 \mathrm{~mL}$ of 2-thiobarbituric acid (TBA) of $0.6 \%$. Tubes were incubated into a tub of hot water of $95{ }^{\circ} \mathrm{C}$ for 45 minutes. After incubation, the tube is cooled in cold water. $1 \mathrm{~mL}$ of $\mathrm{n}$-butanol was added to the tube, then centrifuged at $2000 \mathrm{rpm}$ for 10 minutes. The top layer is taken and measured by a spectrophotometer $\lambda 535 \mathrm{~nm}$. TBARS (thiobarbituric Acid Reactive Substance) which is condensed bioproduct MDA with TBA calculated in $\mu \mathrm{M}$ using the extinction coefficient of $1,56 \times 105 \mathrm{M}-1 \mathrm{~cm}-1$.

\section{G. Statistical Analysis}

Statistical significance was evaluated by one-way analysis of variance (ANOVA). Significance was measured using Fisher's least significant for the exact $p$ values and significant differences are noted in the results. Differences with $\mathrm{p}<0.05$ were considered significant.

\section{RESULTS}

\section{A. Presence of the Flavonoid on Thin Layer Chromatography}

Thin layer chromatography (TLC) indicates the presence of the flavonoid on EAT (Fig. 1). The static phase was using silica gel $60_{\mathrm{F} 254}$, while the motion phase was using buthanol, acetic acid, and water with a ratio of 8: $2: 10$.

\section{B. EAT Decreases SGOT and SGPT Serum Level}

SGOT and SGPT serum was measured as an indicator of cellular injury of liver. Table I shows a significant increase ( $p$ <.01) of SGOT and SGPT enzymes in doxorubicin-induced group compared to control group. Levels both decreased significantly $(p<0.01)$ in the group receiving treatment EAT dose of $1000 \mathrm{mg} / \mathrm{kgW}$ and received induction doxorubicin.

\section{EAT Decreases MDA Serum Level}

The repair mechanisms of liver serum is confirmed by measuring levels of MDA. MDA is used as an indicator of a damage by lipid peroxidation. The increase of MDA indicate oxidation processes or membrane damage caused by free radicals. Fig. 2 shows the doxorubicin significantly increase the MDA serum levels $(\mathrm{p}<0.01)$. Meanwhile, EAT administration after Doxorubicin induction can lower MDA serum levels $(\mathrm{p}<0.05$ at a dose of $500 \mathrm{mg} / \mathrm{kgW}$ and $\mathrm{p}<0.01$ at a dose of $1000 \mathrm{mg} / \mathrm{kgW}$ ).

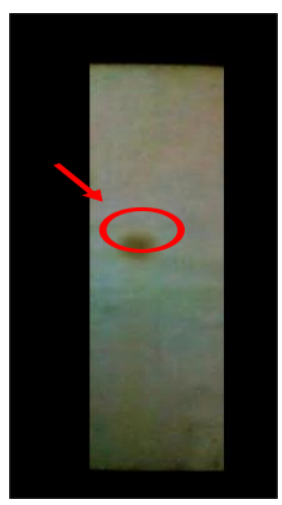

(a)

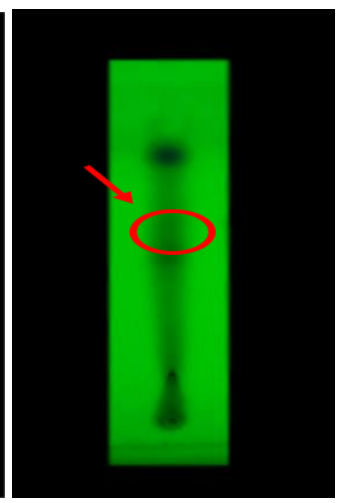

(b)
Figure 1. TLC chromatogram in (a) visible light, (b) UV (366 nm) for the samples of EAT, arrows indicate flavanoids component.

TABLE I. EAT EFFECT ON SGOT AND SGPT SERUM LEVEL

\begin{tabular}{|c|c|c|}
\hline Groups & SGOT (U/L) & SGPT (U/L) \\
\hline Control & $40.38 \pm 2.43$ & $20.52 \pm 4.03$ \\
\hline DOX & $56.26 \pm 4.04^{\mathrm{a}}$ & $36.19 \pm 2.60^{\mathrm{a}}$ \\
\hline EAT 1000 & $40.16 \pm 4.47$ & $20.74 \pm 3.10$ \\
\hline DOX + EAT 500 & $45.01 \pm 4.38^{\mathrm{b}}$ & $28.68 \pm 1.84$ \\
\hline DOX + EAT 1000 & $40.82 \pm 2.63^{\mathrm{b}}$ & $25.90 \pm 7.32^{\mathrm{b}}$ \\
\hline
\end{tabular}

${ }^{\mathrm{a}}$ Significant difference $(\mathrm{P}<0.01)$ compared to the control group value. ${ }^{\mathrm{b}}$ Significant difference $(\mathrm{P}<0.05)$ compared to the Dox group value. Data were expressed as Mean $\pm \mathrm{SD}(\mathrm{n}=6-7$ rats) 


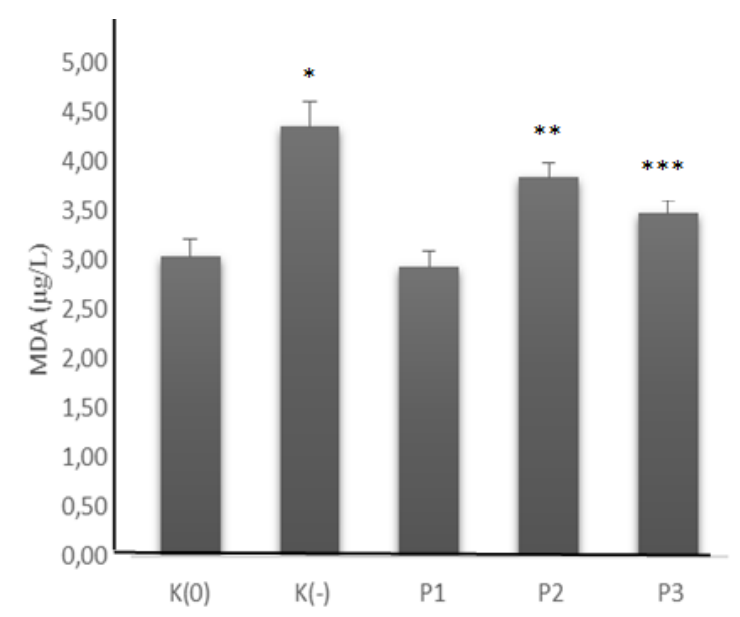

\begin{tabular}{cccccc}
\hline $\mathrm{NaCl} 0.9 \%$ & + & - & - & - & - \\
Doxorubicin & - & + & - & + & + \\
EAT 500 & - & - & - & + & - \\
EAT 1000 & - & - & + & - & + \\
\hline
\end{tabular}

Figure 2. Effect of EAT on MDA serum level. *Significant difference $(\mathrm{P}<0.01)$ compared to the control group value. **Significant difference $(\mathrm{P}<0.05)$ compared to the Dox group value. $* * *$ Significant difference $(\mathrm{P}<0.01)$ compared to the Dox group value. Data were expressed as Mean \pm SD $(n=6-7$ rats $)$

\section{DISCUSSION}

Induction of doxorubicin dose $4.67 \mathrm{mg} / \mathrm{kg}$ day 1 and 8 resulted hepatotoxicity and increased oxidant levels. Oxidative stress and reactive oxygen species (ROS) are involved in the pathogenesis of hepatotoxicity induced by doxorubicin. Doxorubicin increases production of free radicals such as superoxide radicals and hydrogen peroxide hidroxil which has a major role in lipid peroxidation. [10] Previous study showed that doxorubicin lead to liver damage with an increased SGOT, SGPT and $\gamma$-GT serum levels. [11], [12]

EAT restore liver function which had suppressed due to the induction of doxorubicin. SGOT and SGPT are specific enzymes as indicators of hepatic injury. In the case of hepatotoxicity due to infection or other inflammatory reactions, SGPT levels higher or the same height as SGOT. [13] This study showed the opposite, SGOT serum levelsincrease higher than SGPT. It because of cardiotoxicity effect of doxorubicin prior to the hepatotoxicity effect. Increased significant levels of SGOT without increased of SGPT levels are common in cardiac injury. [14]

Malondialdehyde (MDA) is a metabolite of lipid peroxidation by free radicals. Malondialdehyde (MDA) formed when the free radical hydroxyl such as ROS reacts with fatty acid component of cell membrane. [15] The measurement of MDA serum levels can be used as an indicator of the reaction of lipids peroxidation in liver. It also confirm the path-repair mechanisms in cells of the liver hepatocytes. This study shows that the induction of doxorubicin alone significantly increases serum levels of MDA. MDA serum levelsdecreasesafter treatment of
EAT, indicating that lipid peroxidase pathway plays a role in the formation of liver injury.

Phytochemical component contained in garlic chives are alkaloids, phenolic content, glikosid, protein, saponins, flavonoids, etc. Flavanoids component especially allicin associated with the activity of antioxidants or thiol disulfide exchange. Mechanisms of antioxidant action can include (1) suppression of ROS formation either by inhibition of enzymes or by chelating trace elements involved in free radical generation; (2) scavenging ROS; and (3) upregulation or protection of antioxidant defenses. [16]

Thin layer chromatography indicates the presence of the flavonoid on EAT. Flavonoid action involves most of the mechanisms mentioned above. Some of the effects mediated by them may be the combined result of radical scavenging activity and the interaction with enzyme functions. Flavonoids inhibit the enzymes involved in ROS generation, that is, microsomal monooxygenase, glutathione S-transferase, mitochondrial succinoxidase, NADH oxidase, and so forth. [17] Previous studies shown that allicin reacts with free thiol groups and entered the cell membrane. [18] One of the non-protein thiol groups in Allium tuberosum is glutathione (GSH). Allicin reduce free radicals to reduce lipid peroxidation. Allicin reverse hepatocytoxicity by increasing hepatic glutathione (GSH) and GSH-related enzyme. A study explains that Allicin selectively express genes glutathione S-transferase (GST) in the liver. [19]

\section{CONCLUSION}

It can be concluded that doxorubicin causes hepatotoxicity and treatment of EAT is able to restore hepatic function through antioxidant pathways.

\section{ACKNOWLEDGMENT}

The author would like to thank the Ministry of Research, Technology and Higher Education of Indonesia also the University of Jember, which has funded this research.

\section{REFERENCES}

[1] M. Li, Z. Tang, S. Lv, W. Song, H. Hong, X. Jing, Y. Zhang, and $\mathrm{X}$. Chen, "Cisplatin crosslinked $\mathrm{PH}$ sensitive nanoparticles for efficient delivery of doxorubicin," Biomaterials, vol. 35, pp. 38513864, 2014.

[2] D. Chaudhary, S. Khatiwada, S. K. Sah, M. K. Tamang, S. Bhattacharya, and C. B. Jha, "Effect of doxorubicin on histomorphology of liver of wistar albino rats," Journal of Pharmacy and Pharmacology, vol. 4, pp. 186-190, 2016.

[3] R. Mohebbati, A. Abbsnezhad, R. A. Khajavi, S. M. Mousavi, and M. Haghshenas, "Effect of hydroalcholic extract of nigella sativa on doxorubicin-induced functional damage of kidney in rats," Horizon Med. Sci., vol. 22, no. 1, pp. 13-20, 2016.

[4] M. Mohan, B. Shashank, and A. V. Priya. "Protective effect of psidium guajava L. ethanolic extract on doxorubicin-induced nephrotoxicity in rats," Indian Journal of Natural Products and Resources, vol. 5, no. 2, pp. 129-133, 2014.

[5] H. S. A. Seif, "Physiological changes due to hepatotoxicity and the protective role of some medicinal plants," Beni-Suef University Journal of Basic and Applied Sciences, vol. 5, no. 2, pp. 134-146, June 2016. 
[6] K. Adamczewska-Sowińska and J. Turczuk, "Yielding and biological value of garlic chives (Allium tuberosum Rottl. ex Spreng.) depending to the type of mulch," J. Elem., vol. 21, no. 1, pp. 7-19, 2016.

[7] W. Y. Song and J. H. Choi, "Effects of oenanthe javanica and allium tuberosum on lipid content in rats fed a high-fat-highcholesterol diet," Journal of Life Science, vol. 26, no. 3, pp. 302308, 2016.

[8] Y. Feng, X. Zhu, Q. Wang, Y. Jiang, H. Shang, L. Cu, and Y. Cao, "Allicin enhances host pro-inflammatory immune responses and protects against acute murine malaria infection," Malaria Journal, vol. 11, no. 1, pp. 268-276, 2012.

[9] M. N. T. Attia and M. A. Ali, "Hepatoprotective activity of allicin against carbon tetrachloride induced hepatic injury in rats," Journal of Biological Sciences, vol. 6, no. 3, pp. 457-468, 2006.

[10] N. A. El-Shitany, S. El-Haggar, and K. El-desoky, "Silymarin prevents adriamycin-induced cardiotoxicity and nephrotoxicity in rats," Food Chem Toxicol, vol. 46, pp. 2422-2428, 2008.

[11] G. Damodar, T. Smitha, S. Gopinath, S. Vijayakumar, and Y. Rao, "An evaluation of hepatotoxicity in breast cancer patients receiving injection doxorubicin," Annals of Medical and Health Sciences Research, vol. 4, no. 1, pp. 74-79, 2014.

[12] W. Roomi, T. Kalinovsky, N. W. Roomi, W. Rath, and A. Niedzwiecki, "Prevention of adriamycin-induced hepatic and renal toxicity in male balb/c rat by a nutrient mixture," Exp. Ther. Med., vol. 7, no. 4, pp. 1040-1044, 2014.

[13] R. Injac, et al., "Potential hepatoprotective effects of fullerenol $\mathrm{C} 60(\mathrm{OH}) 24$ in doxorubicin-induced hepatotoxicity in Rats with mammary carcinomas," Biomaterials, vol. 29, pp. 3451-3460, 2008.

[14] R. Injac, M. Perse, M. Boskovic, V. Djordjevic-Milic, A. Djordjevic, and A. Hvala, "Cardioprotective effects of fullerenol $\mathrm{C} 60(\mathrm{OH}) 24$ on a single dose doxorubicin-induced cardiotoxicity in rats with malignant neoplasm," Technol Cancer Res Treat, vol. 7, pp. 15-25, 2008.

[15] E. Asni, P. I. Harahap, R. A. Prijanti, I. S. Wanandi, A. W. S. Jusman, and M. Sadikin, "Pengaruh hipoksia berkelanjutan terhadap kadar malondialdehid, glutation tereduksi, dan aktivitas katalase ginjal tikus," Maj Kedokt Indon, vol. 59, no. 12, pp. 595$600,2009$.

[16] A. Mishra, S. Kumar, and A. K. Pandey. (October 2013). Scientific validation of the medicinal efficacy of Tinospora cordifolia. The Scientific World Journal. [Online]. Available: http://dx.doi.org/10.1155/2013/292934

[17] S. Kumar and K. Pandey. (October 2013). Chemistry and biological activities of flavonoids: An overview. The Scientific World Journal. [Online]. Available: http://dx.doi.org/10.1155/2013/162750

[18] T. Miron, I. Listowsky, and M. Wilchek. "Reaction mechanisms of allicin and allyl-mixed disulfides with proteins and small thiol molecules," European Journal of Medicinal Chemistry, vol. 45, pp. 1912-1918, 2010.

[19] C. W. Chih, L. C. Yung, and Y. S. Lee, "Allicin modulates the antioxidation and detoxification capabilities of primary rat hepatocytes," J. Tradit. Complement Med., vol. 2, no. 4, pp. 323330, 2012.

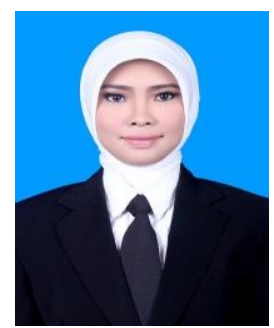

Ika R. Sutejo was born in Surabaya, Indonesia, in 1984. She earned the Doctor of Medicine degree (MD) from University of Jember, Indonesia, in 2009 and the Magister in Medical Biotechnology from Gadjah Mada University, Indonesia, in 2015. In 2009 she joined the departement of Biochemistry, Faculty of Medicinein University of Jember as a lecturer and reasearcher. Her current research interests include cancer, chemopreventive agent, degenerative disease, and antiaging. She is a member of Indonesian Medical Association (IDI) and Indonesian Society for Cancer \& Chemopreventon (ISCC).

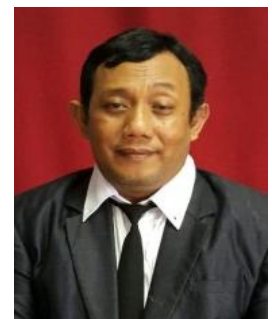

Erfan Efendi was born in Jember, East Java, Indonesia, in 1968. He earned the Doctor of Medicine degree (MD) from Airlangga University, Indonesia, in 1994 and completed his anesthesiology residency from Airlangga University, Indonesia, in 2008. In 1999 he joined the departement of Biochemistry, Faculty of Medicine in University of Jember as a lecturer and reasearcher. His current research interest especially on emergency medicine field. he is a member of Indonesian Medical Association (IDI) and ISDAI. 